\title{
The Importance of Sustained Professional Development for Teaching Statistics - An Example Involving the Mode and Range
}

\author{
Tim Jacobbe (Corresponding Author) \\ University of Florida, 2403 Norman Hall \\ Gainesville, FL 32611, USA
}

Tel: 1-352-273-4232 E-mail: jacobbe@coe.ufl.edu

Bob Horton

Clemson University, 409B Tillman Hall

Clemson, SC 29634-0705, USA

Tel: 1-864-656-5127 E-mail: bhorton@clemson.edu

Received: February 3, 2012 Accepted: February 15, 2012 Published: May 1, 2012

doi:10.5539/ijsp.v1n1p138 URL: http://dx.doi.org/10.5539/ijsp.v1n1p138

\begin{abstract}
This paper presents a progression of events from a case study that explored elementary school teachers' understanding of essential topics in statistics. One particular teacher revealed misconceptions regarding the mode and range during professional development. These misconceptions were corrected, the concepts taught appropriately in the classroom, and then the original misconceptions resurfaced. This example sheds light on the importance of sustained professional development.
\end{abstract}

Keywords: Teachers knowledge, Statistics education, Professional development

\section{Introduction}

Statistics is a relatively new component of the K-12 curriculum. In fact, the efforts of the Quantitative Literacy Project (Schaeffer, 1986) led the National Council of Teachers of Mathematics (NCTM) to first include data analysis as part of its Curriculum and Evaluation Standards (1989). The emphasis has gradually increased in the Principles and Standards for School Mathematics and most notably in American Statistical Association's (ASA) Guidelines for Assessment and Instruction in Statistics Education (GAISE) (2007). These efforts to increase the quantity and quality of statistics content are not isolated to the United States. For example, statistics educators in Australia have been attempting to increase the amount of statistical content in their schools since the release of A National Statement on Mathematics for Australian Schools (Australian Education Council, 1991). All of these efforts built upon the momentum that began with the Quantitative Literacy Project and have eventually led to the inclusion of statistics in the College and Career Readiness Standards that are currently being finalized at a national level in the United States.

The inclusion of statistics in the K-12 curriculum has been an exhausting effort for many statisticians and statistics educators. Now that it is in the curriculum, there is another concern that must be addressed - the preparation of teachers to teach statistical content at the level of sophistication described in the GAISE framework. As Shaughnessy stated almost twenty years ago, “Teachers' backgrounds are weak or nonexistent in stochastics and in problem solving. This is not their fault, as historically our teacher preparation programs have not systematically included either stochastics or problem solving for prospective mathematics teachers" (1992, p. 467). This concern by Shaughnessy was still evident 15 years later, as supported by his statement, "Most K-12 teachers in the United States have very little background in statistics" (p. 995). It likely continues to be a concern.

Over the past several years, statistics educators have called for courses focused on the teaching and learning of statistics to be included in teacher preparation programs (e.g., Jacobbe, 2007; Kader \& Perry, 2002). As important as these are for the preparation of preservice teachers, they cannot address the needs of inservice teachers who have already completed their preservice training. For these teachers, many researchers have recommended and some have implemented professional development programs (e.g., Friel \& Bright, 1998; Watson, 1998).

Professional development is important for changing what transpires in the classroom. For inservice teachers, these opportunities represent one of the only avenues for exposing them to, and helping them master, the advanced content included 
in frequent reform efforts or additions to the curriculum. Research on key characteristics in professional development (e.g., Abell, S., \& Lee, M., 2008; Chval, K., Abell, S., Pareja, E., Musikul, K., \& Ritzka, G., 2008; Loucks-Horsley, Hewson, Love, \& Stiles, 1998) clearly emphasizes the importance of sustained professional development. A report from the Institute of Educational Sciences (2007) confirms this, stating:

Studies that had more than 14 hours of professional development showed a positive and significant effect on student achievement from professional development. The three studies that involved the least amount of professional development (5 - 14 hours total) showed no statistically significant effects on student achievement. (2007, p. iv)

Of the studies cited by IES (2007), only six met this standard of a minimum of 14 hours. On average, the professional development involved in these six studies contained 49 hours of contact hours, which translated to a net increase in students' achievement by 21 percentile points, though it is not always clear on what measures these improvements were noted.

Guskey (2002) identified five levels of professional development evaluation. These include participants' reactions (Level 1), participants' learning (Level 2), organization support \& change (Level 3), participants' use of new knowledge and skills (Level 4), and student learning outcomes (Level 5).

In another study, Guskey (2003) analyzed 13 lists of characteristics of effective professional development, in part to determine if there was overlap between some of the characteristics various organizations recommended. Based on Guskey's analysis, the most common characteristic among the lists was that effective professional development "enhances teachers' content and pedagogical knowledge," which appeared on 12 of the 13 lists. The second most common was that effective professional development "provides sufficient time and other resources," which appeared on 10 of the 13 lists.

In addition to the issue of time, and of more concern to the statistics education community, is the issue of whether or not teachers actually receive training that promotes statistical rather than mathematical thinking. As delMas (2004) eloquently described by pulling on the work of Cobb \& Moore (1997), there is a difference between mathematical and statistical reasoning. According to delMas,

...it is likely that many aspects of statistical and mathematical reasoning are highly similar. The task demands of each discipline, however, may produce different sources of reasoning error. While instruction can be driven and facilitated by contextualization in both disciplines, statistical practice is highly dependent on real world context whereas mathematical practice tends to be removed from real world context (Cobb \& Moore, 1997). (delMas, 2004, p. 91)

This difference is also highlighted in the GAISE framework and is important to consider when developing and implementing professional development programs to improve teachers' preparation to teach statistics. Mathematics educators who themselves were most likely trained in a manner which did not promote statistical thinking focused on dealing with the prevalence of variability - are the ones who are asked to primarily deliver professional development to schools. The result of this may leave teachers being trained in a manner that promotes various measures of central tendency or variation without engaging in the four components of statistical thinking as described in the GAISE framework - Formulating Questions, Collecting Data, Analyzing Data, and Interpreting Results. The remainder of this paper describes a professional development experience that one teacher experienced and then highlights a progression of events that emphasizes the need for sustained professional development situated within statistics.

The progression of experiences described in this paper provides a strong example of why professional development must be a sustained effort. Further, it explores one participant's learning (Level 2) as well as her use of new knowledge and skills (Level 4) as described by Guskey. In particular, it sheds light on the impact a particular professional development opportunity had on one participant's content knowledge as measured on three occasions.

\section{Method}

A case study involving elementary school teachers was conducted in a school district in the USA. The example presented in this paper is from a larger study that explored elementary school teachers' understanding of basic ideas in statistics (for further details see Jacobbe, 2007). Ms. Brown (a pseudonym), who had taught Grade 3 (age 9) for all four years of her teaching career at the time of the study, is the participant discussed in this paper.

Initial contact was made with Ms. Brown through a gatekeeper - the district supervisor for mathematics and science education. Ms. Brown was highly recommended by her principal and district supervisor as she was viewed to be an exemplary teacher of mathematics. Although generalizations cannot be made based on this example, the sequence of 
events provides insight into the importance of sustained development, particularly since the participant had been identified as an exemplary teacher.

Over the course of 18 months, the teachers in the study participated in interviews, completed questionnaires and assessments, and allowed the researcher to observe their classroom at least 12 times. The researcher was also present for professional development training the teachers received. The results reported in this paper are from the researcher's observation of the professional development training as well as accounts from two of the observations involving Ms. Brown. The professional development experience was designed to introduce the teachers to the investigations they would be asked to lead while implementing the curriculum materials. Based on when the professional development was scheduled, it worked out that Ms. Brown was actually scheduled to implement the very same lessons only two days later. The lessons all came from the teachers' manual of a newly developed curriculum by Clemson University entitled Math Out of the Box (Moss, Diaz, Lashley, Moss, \& Sanders 2005), which contained 10 lessons focused on statistics at each grade level. The developers of the Math Out of the Box materials provided the professional development involved in this study. It is important to point out that the professional development providers were not specifically trained in the area of statistics.

\section{Results}

The discussion presented here centers on Ms. Brown's experiences with two fundamental topics in statistics, the mode and the range. The first event stems from the professional development training, which is designated as Day 0. During this experience the first author sat with Ms. Brown as she was participating in the professional development. Two days later, Ms. Brown was observed teaching a lesson. Six days after the first observation of Ms. Brown, she was observed teaching a lesson once again. All three of these experiences (researcher's presence at professional development and two observations of teaching) involved the concepts of the mode and range. Each of these events is described in succession.

\subsection{Professional Development Training (Day 0)}

The professional development training was provided by the authors of the Math Out of the Box materials. The purpose of the training was to introduce some of the statistics lessons to the teachers who would be implementing them during the academic year, as well as to review some of the statistical content that might arise during the lessons.

The context for the lesson introduced during the professional development was the circumference of individuals' wrists. During this training, the researcher sat at the table with Ms. Brown as she was participating in the professional development. The following lineplot was constructed based on data from the participants in the training.

\section{$<$ Figure $1>$}

During Ms. Brown's exploration with the teachers, she looked over at the researcher and indicated, "I know this stuff." She proceeded to say that the mode of the data was 9, because 8 inches occurred as a data value 9 times. However, the mode is the data value or values that occur most often, not the frequency of that value. For this particular data set, the mode was 8 inches since that data point occurred most often (9 times). Ms. Brown reported the range as $9-2$ or 7 . This was obtained by taking the highest frequency (9) minus the lowest frequency (2). For this particular data set, the range should have been reported as 9 (the maximum value represented in the data set) minus 6 (the minimum value represented in the data set, or 3 inches, so, as with mode, Ms. Brown confused the value of the variable in question with the frequency of that value.

The authors believe that it is more valuable to report the range as a range of values (e.g. 6 to 9 inches) in addition to a singular value ( 3 inches) that represents the difference between these values. By reporting the range of values, one knows where the data are situated without having to view the original data set. In contrast, by reporting only a singular value one only knows that the maximum and the minimum are 3 inches apart. In other words, if one knows that the range is 3 inches, one cannot tell if the data range from 6 inches to 9 inches, from 12 to 15 inches, or between any other values 3 inches apart. We further believe that this clarification may help reinforce the idea that the mode and range concern the values of the variables rather than their frequencies.

The error exhibited my Ms. Brown is not uncommon (e.g., Groth \& Bergner, 2006). It was most likely due to confusion regarding the variable in question. The variable in this context was the wrist circumference; however Ms. Brown considered the frequency as the variable. The point made regarding the reporting of the mode above (reporting the mode as 3 inches, from 6 to 9 inches, vs. reporting it only as 3 inches) may have helped Ms. Brown as the range would have been situated within the context of the investigation.

During the professional development training, the correct method to find the mode and the range were discussed. Ms. Brown realized her error (i.e. using the frequencies rather than the values of the variables) and by the end of the training indicated that the mode was 8 inches and the range was 3 inches. Given other contexts as part of the professional development training, Ms. Brown was able to correctly determine the mode and the range. 
Two days after this training, Ms. Brown introduced the same lesson involving wrist circumference to her students and included a discussion of the mode and range. Her success with these ideas is described below.

\subsection{Wrist Circumference Lesson Two Days Later (Day 2)}

During this lesson, students measured the circumference of each other's wrists. The data were collected and organized into a tally chart. Based on the data, the following lineplot was constructed.

$<$ Figure 2>

During a discussion one of the students in Ms. Brown's class introduced the terminology of the range. Comments 1 through 44 are from a discussion that occurred between Ms. Brown and her students regarding the mode and range.

$<$ Table 1>

During this sequence of events, Ms. Brown corrected the misconceptions introduced by students. These were the same misconceptions (comments number 4 and 8 for the range; comment number 34 for the mode) that Ms. Brown exhibited during the professional development training just two days earlier. Based on this lesson, it would seem as though the professional development training was successful.

Six days after the lesson on wrist circumference outlined above, Ms. Brown had another opportunity to work with this same group of students on mode and range. This encounter is described in the following section.

\subsection{Birth Length Lesson (Day 8)}

The context of the lesson observed on this day was students' birth lengths. Students had been asked to bring in their birth lengths (in inches) for the class to investigate. During the morning of this lesson, Ms. Brown also re-introduced the concept of the mode and range for a data set represented once again by a lineplot. However, in her discussion, there was no context, so no variables were identified; further, Ms. Brown did not mention that the values of the variable were identified on the horizontal axis, nor did she indicate that the vertical values, represented by the X's in the chart, showed the frequency, with each $\mathrm{X}$ representing one occurrence. The lineplot was displayed on the board as follows:

$<$ Figure $3>$

During this time, Ms. Brown told the students that the mode of this data set was 7 since this was the highest frequency (note that the correct mode was 6) and the range for this data set was 7 (the highest frequency) minus 2 (the lowest frequency) or 5 (note that the correct range was 3 to 7 or 4). This misconception matches the one Ms. Brown exhibited during the professional development training and the one Ms. Brown had corrected during the class six days earlier (comments 4, 8, and 34 above). This same misconception became an issue yet again during the session on birth lengths, which involved the following lineplot.

$<$ Figure 4>

Comments 45 through 52 represent the conversation between Ms. Brown and a student (the same student who made comments 35 through 44 above) concerning the mode and range after Ms. Brown had explained (incorrectly) how to determine these values.

$<$ Table $2>$

It should be noted that the student who went up to the board and correctly showed that the mode of the wrist sizes in the first lesson was 6 inches (comment number 38) was the same student who questioned finding the mode and range in the birth lengths lesson (comment number 45).

\subsection{Summary of Observations}

Table 3 provides a timeline for what transpired. In the table, Day 0 corresponds to the professional development training, Day 2 corresponds to the wrist sizes lesson, and Day 8 corresponds to the lesson on birth lengths.

$<$ Table 3>

This sequence of events causes a concern over the power of one-day professional development workshops. Even in instances where they appear to have a clear and positive impact on teachers' understanding, it is possible, perhaps even likely, for teachers to revert back to their original misconceptions. The importance of sustained professional development is widely documented (Chval, Abell, Pareja, Musikul, \& Ritzka, 2008: Loucks-Horsley, Hewson, Love, \& Stiles, 1998; Abell \& Lee, 2008; Fraser, Reid, \& McKinney, 2007). Much of this research, however, has focused on sustained PD in an effort to support and reinforce transformation in pedagogy. However the sequence of events described in this paper provides an example of the need to sustain PD in regard to content, particularly in the area of correcting misconceptions. 


\section{Discussion and Implications}

The sequence of events outlined in this paper provides an example of the importance for sustained professional development. It not only calls into concern the quantity of time, but also the quality of training teachers receive in regard to statistics. That isn't to say that the training Ms. Brown received was poor, but that it was not sufficient to overcome her misconceptions. Perhaps if the PD had been more often and had addressed all four components of the statistical process that the GAISE identifies - formulating questions, collecting data, analyzing data, and interpreting results - Ms. Brown may have been able to overcome her misconceptions. Though the training the lead Author witnessed was of high quality, it focused more on collecting and analyzing data, but did not engage her with formulating questions and interpreting results. In the former case, the questions were pre-determined for her, and in the latter case, Ms. Brown did not have to reflect upon and discuss what the results suggested. This may have been a result of the training not being provided by individuals specifically trained in statistics. However, mathematics educators or exemplary teachers are often the ones asked to provide professional development to districts. If the process of statistics is to be emphasized, it is important for statisticians and statistics educators to become more engaged in providing professional development to teachers.

Although the professional development opportunity appeared to affect Ms. Brown's knowledge (Level 2 as described by Guskey), in that she was able to identify the mode and range for data sets after the professional development, and upon her ability to implement this knowledge successfully in the classroom (Level 4 as described by Guskey), in that she was able to teach the concepts appropriately two days after the professional development, this one-day training did not make a lasting impact on Ms. Brown. This is evident by the fact that she reverted to her original misconceptions only eight days after receiving the professional development training.

This situation seems to support the report from the IES and other professional development research (e.g., Chval, Abell, Pareja, Musikul, \& Ritzka, 2008; Loucks-Horsley, Hewson, Love, \& Stiles, 1998; Abell \& Lee, 2008; Fraser, Reid, \& McKinney, 2007), which calls not only for on-going professional development, but the creation of communities of teachers. Despite initial indications that showed the professional development had an impact on Ms. Brown, follow-up observations revealed that the professional development did not last. Perhaps even more troublesome is the fact that she told her students one thing on Day 2 and another on Day 8, and in fact contradicted a student who had learned the ideas correctly during the initial lesson and questioned the teacher when she reversed course on the later day.

Despite the setbacks, the study also revealed reasons for optimism. By the end of the study, Ms. Brown (and indeed the other teachers in the study) had acknowledged an awareness of her lack of content knowledge in the area of statistics and a desire to receive professional development focused on this particular content strand. From the larger study it was clear that although the teachers did not experience lasting gains in their understanding of essential topics in statistics, it caused them to reconsider the suitability of their own content knowledge.

As Gal (2004) points out, one of the biggest obstacles toward the inclusion of statistics in the curriculum is teachers' (and society's in general) disposition toward the discipline of statistics. If teachers have only been exposed to statistical content as a discipline entrenched in procedures rather than the conceptual underpinnings of the processes, then they will not realize that there is a gap in their knowledge. For all the teachers in the case study, the interaction caused the teachers to question their dispositions toward statistics. In other words, this interaction problematized the awareness of their knowledge.

Once teachers recognize new viewpoints or what may be lacking in their own understanding, problematization occurs. Problematizing teachers' knowledge is essential for professional development to be successful in changing teachers' preparedness for teaching (Cobb \& Bauersfled, 2005). Teachers who realize they have a lack of understanding in a particular area are more likely to benefit from professional development focused on content. The teachers involved in this study provide an example that illustrates the importance of such a realization. At the beginning of the study, the teachers preferred activities they could use in their classrooms over developing their own content knowledge. At the end of the study, they preferred professional development focused on content. With the problematization they experienced, the teachers would be more likely to absorb the content introduced during sustained professional development that is fundamental to true understanding and the processes of statistical inquiry. Though the initial professional development had not had the desired effect in terms of knowledge and pedagogy, the teachers' recognition of their gaps suggested that, in the long term, the goals for understanding would be met.

\section{Conclusion}

This study confirmed that a single effort at correcting teachers' misconceptions may not be successful. Professional development in the area of statistics might be more successful if it were offered on a more sustained basis and focused on the statistical processes as described in the GAISE framework. Further studies are necessary to investigate the effect of various professional development opportunities on the statistical content knowledge of elementary school teachers; 
however it is clear that one-shot professional development will not overcome some teachers' misconceptions.

\section{References}

Abell, S., \& Lee, M. (2008). Making the most of professional development. Science and Children, 45, 63-64.

Australian Education Council. (1991). A national statement on mathematics for Australian schools. Carlton, Australia: Author.

Chval, K., Abell, S., Pareja, E., Musikul, K., \& Ritzka, G. (2008). Science and mathematics teachers' experiences, needs, and expectations regarding professional development. Eurasia Journal of Mathematics, Science \& Technology Education, 4(1), 31-43.

Cobb, G. W., \& Moore, D. (1997). Mathematics, statistics, and teaching. American Mathematical Monthly, 104, 801-823. http://dx.doi.org/10.2307/2975286

DelMas, R. C. (2004). A comparison of mathematical and statistical reasoning. In D. Ben-Zvi \& J. Garfield (Eds.), The challenges of developing statistical literacy, reasoning, and thinking, pp. 79-96. Dordrecht, The Netherlands: Kluwer.

Fraser, C., Kennedy, A., Reid, L., \& McKinney, S. (2007). Teachers' continuing professional development: Contested concepts, understandings and models. Journal of In-Service Education, 33(2), 153-169. http://dx.doi.org/10.1080/13674580701292913

Groth, R. E., \& Bergner, J. A. (2006). Preservice elementary teachers' conceptual and procedural knowledge of mean, median, and mode. Mathematical Thinking and Learning, 8, 37-63. http://dx.doi.org/10.1207/s15327833mt10801_3

Guskey, T. R. (2002). Does it make a difference? Evaluating professional development. Educational Leadership, 59(6), 45-51.

Guskey, T. R. (2003). Analyzing lists of the characteristics of effective professional development to promote visionary leadership. NASSP Bulletin, 87(637), 4-17. http://dx.doi.org/10.1177/019263650308763702

Jacobbe. (2007). Elementary school teachers' understanding of essential topics in statistics and the influence of assessment instruments and a reform curriculum upon their understanding. [Online] Available: http://www.stat.auckland.ac.nz/ iase/publications/dissertations/dissertations.php

Kader, G., \& Perry, M. (2002). A statistics course for elementary and middle school teachers. In B. Phillips (Ed.), Proceedings of the Sixth International Conference on Teaching Statistics, Cape Town, South Africa: International Statistical Institute and International Association for Statistical Education. [Online] Available: http://www.stat.auckland.ac.nz/ iase/publications.

Loucks-Horsley, S., Hewson, P., Love, N., \& Stiles, K. (1998). Designing professional development for teachers of science and mathematics. Thousand Oaks, CA: Corwin Press, Inc.

Moss, D., Diaz, D., Lashley, E. Moss, W., \& Sanders, S. (2005). Developing Algebraic Thinking: Plotting and Growing, Teacher's Manual, Third Grade. Burlington, NC: Carolina Biological Supply.

National Council of Teachers of Mathematics. (1989). Curriculum and evaluation standards for school mathematics. Reston, VA: Author.

National Council of Teachers of Mathematics. (2000). Principles and standards for school mathematics. Reston, VA: Jacobbe.

Yoon, K. S., Duncan, T., Lee, S. W.-Y., Scarloss, B., \& Shapley, K. (2007). Reviewing the evidence on how teacher professional development affects student achievement (Issues \& Answers Report, REL 2007-No. 033). Washington, DC: U. S. Department of Education, Institute of Education Sciences, National Center for Education Evaluation and Regional Assistance, Regional Educational Laboratory Southwest. Retrieved from http://ies.ed.gov/ncee/edlabs. 
Table 1. Wrist circumference lesson transcript

\begin{tabular}{lll}
\hline Number & Person & Comment \\
\hline 1 & Ms. Brown & $\begin{array}{l}\text { [To a particular student] You brought up a good } \\
\text { word earlier. What was that word? }\end{array}$ \\
2 & Student & Range \\
3 & Ms. Brown & $\begin{array}{l}\text { What is the range? } \\
\text { Range is the difference between the biggest num- } \\
\text { ber of X's and the smallest number of X's. }\end{array}$ \\
5 & Student & Anyone else? \\
6 & Ms. Brown & $\begin{array}{l}\text { Difference between the most popular and least } \\
\text { popular. }\end{array}$ \\
7 & Student & Can you show me?
\end{tabular}

The student showed that there were 10 X's at 6 and 2 X's at 5 .

9

10

11

12

13

14

15

16

17

18
Student

Ms. Brown

Student

Ms Brown

Student

Ms. Brown

Student

Ms. Brown

Student

Ms. Brown

Student
So you take the 10 minus 2 to get a range of 8 .

Anyone else? How many number choices did we have when we recorded the information?

15

How many measurements, in inches, did we actually have?

3

What measurement is the highest we used?

6 inches

Was that the highest number of inches that we used?

No. We used 7 as the highest.

What was the smallest length?

5

Ms. Brown wrote the word "Range" on the board with the numbers 7 and 5 beneath the word.

19

20

21
Ms. Brown

Student

Ms. Brown
I want to know the difference between these two numbers. What do I do?

Add them

Close 


\begin{tabular}{|c|c|c|}
\hline Number & Person & Comment \\
\hline 22 & Student & Subtract them \\
\hline 23 & Ms. Brown & So, $7-5=2$. Guess what that is. \\
\hline 24 & Student & The range. \\
\hline 25 & Ms. Brown & I made a mistake. Two what? \\
\hline 26 & Student & Inches \\
\hline 27 & Ms. Brown & $\begin{array}{l}\text { So it is not the number of X's. You just look down } \\
\text { here (pointing to the numbers below the line in the } \\
\text { lineplot). }\end{array}$ \\
\hline 28 & Student & I do not get how it is 7 and 5 . \\
\hline 29 & Ms. Brown & We took the greatest number we had and the least. \\
\hline 30 & Student & We took the most before. \\
\hline 31 & Student & What about the mode? \\
\hline 32 & Ms. Brown & Let's talk about the mode. \\
\hline 33 & Student & $\begin{array}{l}\text { I think I know the mode. I think the mode is the } \\
\text { opposite of the range, so it is } 7+5=12 \text {. }\end{array}$ \\
\hline 34 & Student & $\begin{array}{l}\text { I think when you do the number of X's, the highest } \\
\text { amount of X's is } 10 \text {, so the mode would be } 10 \text {. }\end{array}$ \\
\hline 35 & Ms. Brown & $\begin{array}{l}\text { (Calling on a particular student) What did you say } \\
\text { about the mode? }\end{array}$ \\
\hline 36 & Student & $\begin{array}{l}\text { It would be the measurement that has the most X's } \\
\text { above it. }\end{array}$ \\
\hline 37 & Ms. Brown & What would that be? \\
\hline 38 & Student & $\begin{array}{l}6 \text { (The student went up to the board and pointed to } \\
\text { it.) }\end{array}$ \\
\hline 39 & Ms. Brown & So what is the mode? \\
\hline 40 & Student & 6 \\
\hline 41 & Ms. Brown & Did I have to add anything? \\
\hline 42 & Student & No \\
\hline 43 & Ms. Brown & $\begin{array}{l}\text { I just have to say } 6 \text { inches. Did I have to count } \\
\text { X's? }\end{array}$ \\
\hline 44 & Student & You could just look at it. \\
\hline
\end{tabular}


Table 2. Birth length lesson transcript

\begin{tabular}{|c|c|c|}
\hline Number & Person & Comment \\
\hline 1 & Student & $\begin{array}{l}\text { We [a group of students working on analyzing a } \\
\text { data set together] disagree how to find the mode } \\
\text { and range. }\end{array}$ \\
\hline 2 & Ms. Brown & How are you trying to find the mode? \\
\hline 3 & Student & $\begin{array}{l}\text { I think you should look at the bottom of the line } \\
\text { plot rather than the number of X's. Well I guess } \\
\text { you look at the number of X's to see which birth } \\
\text { length happened most often. So I think the mode } \\
\text { should be } 21 \text {. }\end{array}$ \\
\hline 4 & Ms. Brown & $\begin{array}{l}\text { How are other people in your group finding the } \\
\text { mode? }\end{array}$ \\
\hline 5 & Student & $\begin{array}{l}\text { They are saying that the mode is the most number } \\
\text { of X's, so they say it is } 8 \text {. }\end{array}$ \\
\hline 6 & Ms. Brown & $\begin{array}{l}\text { The mode is the most number of X's, so it is } 8 \text {. I } \\
\text { like your thinking in trying to get } 21 \text {, but the mode } \\
\text { is } 8 \text { here. What were you thinking about with the } \\
\text { range? }\end{array}$ \\
\hline 7 & Student & $\begin{array}{l}\text { Well, I am probably wrong. I was thinking that } \\
\text { the range was the difference between the smallest } \\
\text { birth length and the biggest birth length. I thought } \\
\text { it was } 6 \text { (this was from } 25-19 \text { ), but they are saying } \\
\text { that it is } 7 \text { (this was from } 8-1 \text { ). }\end{array}$ \\
\hline 8 & Ms. Brown & Yes, it is 7. \\
\hline
\end{tabular}

Table 3. Timeline for Ms. Brown's misconception regarding the range

\begin{tabular}{|c|c|}
\hline Day & Event \\
\hline 0 & $\begin{array}{l}\text { Professional Development Training introduced the concepts of mode and range. Dur- } \\
\text { ing this training, Ms. Brown originally exhibited the misconceptions regarding the } \\
\text { concepts of mode and range. }\end{array}$ \\
\hline 0 & $\begin{array}{l}\text { Ms. Brown's misconceptions were corrected by her experiences with the lesson in the } \\
\text { professional development training. }\end{array}$ \\
\hline 2 & $\begin{array}{l}\text { Ms. Brown was able to correct the same misconceptions she had exhibited during the } \\
\text { professional development training when they were exhibited by her students. }\end{array}$ \\
\hline 8 & $\begin{array}{l}\text { Ms. Brown reverted to her original misconceptions as more time had passed between } \\
\text { the professional development training and her coverage of the mode and range. Early } \\
\text { in the day, Ms. Brown taught the students how to find the mode and range of a data } \\
\text { set incorrectly, using an example without context. This teaching contradicted the way } \\
\text { she originally introduced the concepts to the students on Day } 2 \text {. }\end{array}$ \\
\hline 8 & $\begin{array}{l}\text { Ms. Brown, in error, informed a student that he was incorrect in the manner he found } \\
\text { the mode and range. This contradicted the responses she praised } 6 \text { days earlier. }\end{array}$ \\
\hline
\end{tabular}




\begin{tabular}{cccc} 
& & X & \\
& & $X$ & \\
& $X$ & $X$ & \\
& $X$ & $X$ & \\
& $X$ & $X$ & \\
$X$ & $X$ & $X$ & \\
$X$ & $X$ & $X$ & \\
$X$ & $X$ & $X$ & $X$ \\
$X$ & $X$ & $X$ & $X$ \\
\hline 6 & 7 & 8 & 9
\end{tabular}

Figure 1. Wrist circumference (in inches)

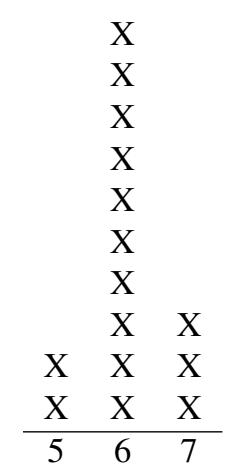

Figure 2. Wrist circumference (in inches)

\begin{tabular}{ccccc} 
& & & $\mathrm{X}$ & \\
& $\mathrm{X}$ & & $\mathrm{X}$ & \\
& $\mathrm{X}$ & & $\mathrm{X}$ & \\
& $\mathrm{X}$ & & $\mathrm{X}$ & \\
$\mathrm{X}$ & $\mathrm{X}$ & & $\mathrm{X}$ & $\mathrm{X}$ \\
$\mathrm{X}$ & $\mathrm{X}$ & $\mathrm{X}$ & $\mathrm{X}$ & $\mathrm{X}$ \\
$\mathrm{X}$ & $\mathrm{X}$ & $\mathrm{X}$ & $\mathrm{X}$ & $\mathrm{X}$ \\
\hline 3 & 4 & 5 & 6 & 7
\end{tabular}

Figure 3. Lineplot in Ms. Brown's class

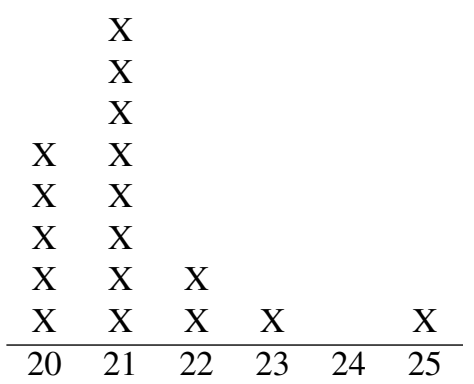

Figure 4. Birth length (inches) 